\title{
FIGURAS DA INFÂNCIA: INSCRIÇÕES, CIRCUNSCRIÇÕES E INCÊNDIOS
}

\author{
Flávia Schilling 1 \\ Universidade de São Paulo, Brasil \\ Patrícia Helena Ferreira ${ }^{2}$ \\ Rede Municipal de Educação de São Paulo, Brasil
}

\begin{abstract}
Resumo
É impossível resistir à tentação de escrever, neste breve artigo, sobre avessos e contrapelos. Pois, afinal, estamos sob a égide de Incêndios que, ao contrário do que se espera hoje, é uma história sem final feliz. Sem final, talvez. A contrapelo das figuras contemporâneas de infância, em Incêndios há a presença das genealogias e suas possibilidades de liberdade, centradas na memória, na dor, na luta, na resistência. Há, nestas mesmas genealogias, ao mesmo tempo, suas muitas prisões. Há miragens de liberdade centradas nas figuras femininas que conseguem olhar, de olhos bem abertos. Há a palavra - difícil e frágil - que se apresenta no cantar. Há silêncios a serem decifrados (e respeitados) e há, principalmente, a libertação via domínio da palavra: aprender a ler, aprender a escrever, aprender a contar, aprender a falar, aprender a pensar. Há, como seu avesso, a impossibilidade de colocar em palavras, a inutilidade de aprender a contar, aprender a falar, aprender a pensar. Além dos grandes discursos, há uma proposta de decifrar pequenos gestos, pistas, enigmas. Todavia, inspirando-nos no conceito de campo de visão e na ideia de visão periférica, como a capacidade do indivíduo enxergar pontos ao redor de seu campo visual, trabalharemos no artigo o duplo infância-felicidade afetado pelo discurso do risco e procuraremos focar algumas questões presentes no que chamamos de enxurrada discursiva acerca do infantil, em especial, o apaziguamento da memória, da dor, da luta, da resistência e do acontecimento. Para tanto percorremos a discussão sobre a proteção/ cuidados da infância com suas figuras do risco; as figuras das crianças felizes com o deslocamento contemporâneo da ideia de resistência para o de resiliência, como sendo a capacidade de enfrentar as adversidades. Assim tentamos captar, na angular formada, a racionalidade vigente de uma época e ainda perceber que nela, supostamente, não há nada de inaugural, somente rearranjos e deslocamentos, mas que produzem, efetivamente, efeitos nos/de sujeitos.
\end{abstract}

Palavras-chave: infância; governo; risco; felicidade; memória.

\section{Childhood figures: inscriptions, circumscriptions and fires}

\begin{abstract}
In this brief article, it is impossible to resist the temptation to write about duplicities and opposites. After all, we are discussing Fires, which, contrary to what is currently expected, is a story without a happy ending. Or even without an ending, maybe. In contrast with the contemporary figures of childhood, in Fires there is the presence of genealogies and their possibilities of freedom, centered in memory, pain, struggle and resistance. At the same time, these genealogies may be prisons of the imagination. There are mirages of freedom centered in feminine figures that are able to look, with eyes wide open. There is the word hard and fragile - that presents itself in singing. There are silences to be deciphered (and
\end{abstract}

\footnotetext{
${ }^{1}$ E-mail: flaviaischilling@gmail.com

2 E-mail: patihell@yahoo.com.br
} 
respected) and there is, primarily, freedom through mastering of the word: learning to read, learning to write, learning to tell, learning to talk, learning to think. There is, as its opposite, the impossibility of putting into words, the inutility of learning to tell, learning to talk, learning to think. Beyond the big speeches, there is a proposal for deciphering small gestures, clues and enigmas. However, gathering inspiration from the concept of field of view and the idea of peripheral vision--understood as the capacity of an individual to see elements outside the center of gaze-I discuss in this paper the duplicitous childhoodhappiness-as-affected-by-liabilities discourse, and focus on some questions that arise from what I call a "discursive thunderstorm" concerning childhood, in particular the appeasement of memory, of pain, of fight, of resistance and of events. For this purpose, I analyze discussions about protection / child-care and their calculations based on liability ; the figures of children dealing with the contemporary shift from the idea of resistance to that of resiliency, as being the capacity to face adversity. I try to capture, in the meetingpoints of these discussions, the current rationality of our epoch, while recognizing that in fact there is nothing new, only reshufflings and movements that create effects in individuals.

Keywords: childhood; governmentality; risk; happiness; memory

\section{Figuras de la infancia: inscripciones, circunscripciones e incendios}

\section{Resumen}

Se nos hace imposible resistir a la tentación de escribir, en este artículo, sobre lo que se coloca al revés y a contramano. Estamos, al final de cuentas, trabajando con el texto Incendios que, al contrario de lo que hoy se espera, es una historia sin final feliz. Sin final, tal vez. O con finales y comienzos distintos. A contramano de las figuras contemporáneas de infancia, en Incendios es posible encontrar genealogías - sus posibilidades de libertad, centradas en la memoria, en el dolor, la lucha y la resistencia. Hay, en estas mismas genealogías, al mismo tiempo, posibilidades de muchas prisiones. Hay espejismos de libertad centrados en figuras femeninas que consiguen mirar, con ojos bien abiertos. Hay palabra - difícil y frágil - que se presenta al cantar. Hay silencios a ser descifrados (y respetados) y hay, principalmente, la liberación por el medio de la palabra: aprender a leer, aprender a escribir, aprender a contar, aprender a hablar, aprender a pensar. Hay, como su revés, la imposibilidad de colocar en palabras, la inutilidad de aprender a contar, aprender a hablar, aprender a pensar. Más allá de los grandes discursos, hay una propuesta de descifrar pequeños gestos, huellas, enigmas. Inspirándonos en el concepto de campo de visión y en la idea de visión periférica como la capacidad del individuo de ver puntos alrededor de su campo visual, trabajaremos en este artículo con el par infancia-felicidad afectado por el discurso del riesgo e intentaremos colocar algunas preguntas del presente en lo que chamamos de tempestad discursiva sobre lo infantil, en especial a los que tratan de apaciguar la memoria, el dolor, la lucha, la resistencia: el acontecimiento. Para tanto traeremos la discusión sobre la protección/cuidados de la infancia con sus figuras del riesgo; las figuras de los niños felices con el desplazamiento contemporáneo de la idea de resistencia para la de resiliencia, como la capacidad de enfrentar las adversidades. Así, intentamos capturar, en la angular formada, la racionalidad de una época e percibir que en ella no hay nada inaugural, solamente nuevos arreglos y desplazamientos, pero que producen, sin duda, efectos en los/de sujetos.

Palabras clave: infancia; gobierno; riesgo; felicidad; memoria 
FIGURAS DA INFÂNCIA: INSCRIÇÕES, CIRCUNSCRIÇÕES E INCÊNDIOS

\author{
Ralph (com Simon): \\ Você não está vendo a retranca dele... \\ A gente chama isso de problema de visão periférica
}

(MOUAWAD, 2013, p. 35)

"Incêndios", assevera Wadji Mouawad, retoma a reflexão da questão da origem, iniciada anteriormente com a escrita e a encenação de outra peça teatral de sua autoria, "Litoral" (MOUAWAD, 1999). Tal problemática, ainda segundo Mouawad, pode, conforme a perspectiva tomada, ter vários inícios, inícios esses que acabam por se confluir nas encruzilhadas (i)lógicas das histórias que ali são cerzidas. Histórias que se iniciam em infâncias diversas, cortadas pela violência, pela dor, pela luta, pela resistência e pelos deslocamentos que tendem a contrariar a previsibilidade e a linearidade dos fatos.

As angulares formadas por esses encontros e deslocamentos geram naqueles que se deixam tombar pela sua escrita, um efeito de "chamuscamento" provocado por um fogo que arde à brasa pequena, contínuo e poderoso, sem precisar fazer grandes alardes. Contudo, o efeito que se produz é o de ressecamento e avaria, sufocamento a céu aberto.

A “questão da origem" poderia também nos remeter a ideia do trágico e de suas raízes na democracia ateniense, dos conflitos que traduzem aspectos da experiência humana que marcam uma etapa da formação do homem interior, do homem como sujeito responsável (VERNANT, 2011). A entrada no campo da dramaturgia serviu-nos, porém, como pista metodológica para apurarmos a possibilidade de adentrarmos a uma análise possível, um trampolim para deslocarmo-nos do texto a partir dos impactos que ele mesmo produziu.

Inspirando-nos no conceito de campo de visão (LAZZARATTO, 2012), técnica da dramaturgia em que os deslocamentos são gerados a partir de uma movimentação feita por outro ator que estiver ou entrar em seu campo de visão, à moda de improvisação de um texto fixo, voltaremos nossa atenção ao que nos afetou como inscrição das figuras de infância em "Incêndios". 
A partir (e a despeito) das marcações sobre a infância presentes e ausentes no texto procuramos traçar uma linha de análise. Ancorados, ainda, na ideia de visão periférica, capacidade do indivíduo enxergar pontos ao redor de seu campo visual - visão pouco rica em detalhes, quase esfumaçada, mas fundamental na captura dos movimentos, intentamos, à moda de Jeanne ${ }^{3}$, mergulhar longe de uma geometria precisa que estrutura (ou objetiva a estruturar) a vida na contemporaneidade: o duplo infância-felicidade, na tentativa de captarmos funcionamentos e deslocamentos das inscrições da infância, em especial a desenhada com o advento da Modernidade.

Para tal, nosso campo de visão, também afetado pelo seu avesso, que podemos supor está dado pelo discurso do risco, procurará focar algumas questões presentes no que chamamos de enxurrada discursiva acerca do infantil, em especial, o apaziguamento da memória, da dor, da luta, da resistência, do acontecimento, enfim.

No entendimento de que ocupamos, todos, um lugar na trama que emoldurou o sujeito moderno e entendendo que não há como deixarmos o jogo, pois dele fazemos parte e somos nele constituídos, quiçá nossa possibilidade seja a de criar um ponto de vista tal qual um belvedere, uma "varanda sobre o mundo", diria Jorge Ramos do Ó, "e o que desse plano distanciado alcançará só pode corresponder ao que os instrumentos teóricos que ele próprio maneja lhe permitem descortinar" (2003, p. 5). Desse lugar, mirarmos alguns pontos, aproximarmo-nos de alguns mais específicos, para talvez tentarmos captar, na angular formada, a racionalidade vigente de uma época e ainda perceber que nela, supostamente, não há nada de inaugural, somente rearranjos e deslocamentos, mas que produzem, efetivamente, efeitos nos/de sujeitos, ou como nos diria Michel Foucault (2008, p. 262), que “há 'algo completamente diferente': não absolutamente seu segredo essencial e sem data, mas o segredo que elas são sem essência ou que sua essência foi construída peça por peça a partir de figuras que lhe eram estranhas".

\footnotetext{
${ }^{3}$ Uma das personagens centrais da peça.
} 
Nesta perspectiva, figuras são formadas. Há a possibilidade de se pensar em figuras que começam a aparecer no cenário, que começam a ser desenhadas, e que de repente parecem existir com vida própria nas instituições. Tão estranhas e, de súbito, tão naturais. Segundo a coletânea Figuras de Foucault (RAGO; VEIGA-NETO, 2006), uma figura pode ser considerada:

[...] forma exterior, o entorno externo de um corpo, configuração; conjunto dos traços gráficos que reproduzem alguém ou algo (real ou imaginário); a representação gráfica, não necessariamente proporcional ou fiel, de alguém ou de algo; qualquer representação visual (esculpida, pintada, gravada, etc.) de uma forma inspirada na realidade ou na imaginação; (...) imagem sem nitidez, forma apenas vislumbrada, entrevista, vulto; representação simbólica de algo; imagem que remete a alguma coisa, símbolo, emblema, alegoria; personagem ou personalidade de importância; ator, intérprete, comediante que, em uma peça, representa um ou mais personagens; diabo, demônio... (RAGO; VEIGA-NETO, 2006, contracapa).

Há melhor definição do que é uma pesquisa, de seus encontros e intuições, da captura sempre incompleta das figuras, vultos, imagens, personagens que nos instigam? Deste olhar periférico, que vê vultos, que de repente percebe personagens, diabos e demônios que não sabíamos que lá estavam e que nos informam sobre como nos tornamos, ao final, o que somos?

\section{Um primeiro olhar sobre a figura infantil: a indicação da proteção e o império psi}

Não estamos sem recursos, as palavras são horríveis. É preciso ficar lúcido. Enxergar. Fazer como os antigos: tentar ler presságios no voo dos pássaros

(MOUAWAD, 2013, p. 80)

Os discursos sobre a infância, na atualidade, emolduram um brinde a um olhar cada vez mais pastoral e atento sobre as crianças e a infância (FERREIRA, 2013). Disparam a nossa volta enunciados que anunciam a criança como o futuro da nação, que enaltecem a inocência da infância, que atrelam a felicidade da infância à existência de pais amorosos e dedicados, que narram as crianças como sementes para a paz e a esperança. 
Embora discursada como positividade e possibilidade, a infância também transita por domínios da incerteza e do imprevisível, quando os encontros de angulares, por muitas vezes, dão a ver situações de violência e expropriação de direitos. No caso de Nawal, seu próprio encontro com a maternidade deu-se na circunscrição da própria infância e o desenrolar da sua história teve desdobramentos outros daqueles esperados para uma vida feliz. "Vai nua, com teu ventre e a vida que ele encerra. Ou então fica e ajoelha, Nawal, ajoelha" (MOUAWAD, 2013, p. 44). A escolha que daí parte transtorna todos os caminhos previsíveis de uma história considerada como feliz. Uma faca plantada no pescoço.

Como analisa Dora Lilia Marín-Díaz (2010), muitos sentimentos contraditórios acerca da infância povoam o imaginário dos cidadãos nas sociedades contemporâneas. Tais sentimentos configuram-se em torno de quatro eixos sobre os quais se concentram os debates mais recentes a propósito da infância:

\begin{abstract}
a criminalidade - entre as crianças em perigo e as crianças perigosas; a sexualidade - entre o abuso sexual de menores e a erotização dos corpos infantis; o trabalho - entre o trabalho infantil e o direito e a necessidade de trabalho de algumas crianças; e a educação - entre os direitos e os deveres educativos das crianças (MARÍN-DÍAZ, 2010, p. 205).
\end{abstract}

Ao redor desses eixos, continua a autora, questões morais, interesses políticos e econômicos entrecruzam-se, com objetivo de manter, transformar ou controlar o que são e o que podem ser futuramente. Um campo discursivo é, então, configurado "por e através de uma série complexa de relações e interações entre discursos provenientes de sistemas e ordens diferentes" (MARÍN-DÍAZ, 2010, p. 205). Os discursos da psicologia, medicina, pedagogia e do direito, agregam-se aos discursos e práticas da cultura popular, da mídia, formando um conjunto de vozes, práticas e saberes acerca do infantil.

A conclamação de um lugar especial para a infância, espaço de intervenção das políticas públicas sociais, principalmente na área da saúde e educação, tem chamado a atenção de estudiosos de diferentes áreas da ciência, principalmente a partir do início do século XX. Tais estudos, de ampla magnitude, têm inventariado, pesquisado, medido e calculado características físicas e psicológicas dessa fase do desenvolvimento humano, como também estudado, à luz das pesquisas anteriores, as condições (im)próprias da sua vida, criando padrões de aceitabilidade para o 
que se chama de desenvolvimento normal. Por fim, em nome deste último, têm oferecido fórmulas de atuação que vão da esfera estatal à privada, no sentido de promoção de uma melhor vida para o infante, e como consequência, para o adulto.

Trata-se, por um lado, de um empenho em proteger as crianças. As normativas que despontaram a partir do último quartel do século XX cada vez mais dispõem a infância como foco de atenção: são tratados internacionais, constituições, diretrizes e pareceres na área da educação, saúde, assistência social - um olhar atento sobre essa população, protegida agora pelo direito. Vê-se a diligência de organizações multilaterais que atuam conjuntamente denunciando, cobrando e incentivando práticas junto aos infantis, de modo a colocá-los a salvo de toda forma de negligência, discriminação, exploração, violência, crueldade e opressão, tal como a carta magna brasileira de 1988 apregoa. No documento "Um mundo para as crianças", datado de 2002, representantes de governos dos cinco continentes convocam todos os membros da sociedade para uma aliança mundial, firmando compromissos com os objetivos de: pautar as crianças em primeiro lugar; erradicar a pobreza - investir na infância; não abandonar nenhuma criança; cuidar de cada criança; educar cada criança; proteger as crianças da violência e da exploração; proteger as crianças da guerra; ouvir as crianças e assegurar sua participação/proteger a Terra para as crianças; enfim, construir "um mundo para as crianças" (ORGANIZAÇÃO DAS NAÇÕES UNIDAS, 2002, p. 70).

Na configuração hodierna, o investimento na infância representa, ao mesmo tempo, uma resposta ao presente e um lançamento das bases para um futuro planificado, e por sua vez, cada vez mais controlado e circunscrito. Variáveis têm que ser diuturnamente acompanhadas, com objetivo de minorar os desvios e favorecer o desenvolvimento de fatores de resiliência, autoestima, autoproteção e independência econômica. O governo da infância tem sido então, tomado como problemática mundial e, ao mesmo tempo, como possibilidade de intervenção certeira das políticas sociais, dado que as crianças pequenas são consideradas "maleáveis" e suscetíveis à influência externa. Tal discursividade, segundo o referencial analítico aqui adotado, opera a partir da noção de risco. 


\section{Infantes: figuras do risco}
Com certeza, com certeza, com certeza, tem algumas vezes, assim, na vida, em que é preciso agir. (MOUAWAD, 2013, p. 80)

Uma vida que é gerada. “Meu ventre está cheio de ti. É uma vertigem, não é? É magnífico e horrível, não é? É um abismo e é como a liberdade das aves selvagens, não é?" (MOUAWAD, 2013, p. 41). Vida que traz para os que a produziram um misto de espanto e soberania, medo e ousadia. A permissão ou a proibição para sua continuidade não dependem somente dos que a provocaram, mas de uma complexa teia de relações, interdições, morais e acasos que se constroem a partir dos encontros. Se tais encontros partem, ao nosso entender, das armadilhas do existir e da imanência das linhas de força que atuam sobre o vivido, qual vontade de poder acaba por sucumbi-los de tal forma a esquadrinhá-los, alinhá-los, produzi-los uniformes?

Entendemos que a figura de infância produzida ao longo dos séculos, em especial com o advento da Modernidade, se autoperfaz no sentido de alimentar a ideia de fragilidade e perigo, porvir e controle. É preciso cercá-la para que o informe tome corpo. É necessário alertá-la dos perigos do existir. Governo da bios.

A estratégia preconizada nas atuais políticas para a primeira infância baseiase na noção de risco social, ou seja, o oferecimento de um acompanhamento e cuidado "antecipados" que poderá eliminar fatores que contribuem para o aumento da pobreza, da fome e da mortalidade infantil, controlando assim o campo probabilístico da gestão da população. Tal discurso encontra-se vinculado fortemente ao equacionamento de uma política econômica autorreguladora, ao fomento tecnológico neoliberal de governo.

A noção de risco foi operada por diversas ciências, tais como a sociologia, a psicologia e é força motriz da estatística social, quando relacionada à gestão de populações, fazendo parte de cálculos de organização e intervenção social.

O risco é "fabricado" a partir da produção de marcadores da normalidade, os quais se relacionam mais a questões individuais do que sociais, numa lógica de 
responsabilização do sujeito que se encontra na condição de risco. Segundo Simone Hünning (2007), podemos pensar num duplo movimento quando pensamos no risco, quando atrelado à infância ou adolescência: o risco para a criança/adolescente, ou seja, dado a partir da falta de condições para seu desenvolvimento pleno (nesse caso estaríamos falando das condições mínimas de cidadania - moradia, alimentação, cuidados, educação, saúde etc.) e o risco representado pela criança/adolescente quando os mesmos afrontam modos de vida já estabelecidos, tais como os que desde pequenos moram nas ruas, frequentam gangues, apresentam comportamentos violentos. Tal diferenciação, operando numa lógica de inclusão/exclusão, não tem contornos nítidos: a vulnerabilidade e a ameaça aproximam-se na medida em que as diferenças são tomadas, a priori, como perigosas.

A partir dessa lógica, os riscos que a infância está submetida (ou representa) encontram-se no centro das discussões e disputas no plano ideológico, das políticas sociais e das iniciativas práticas. Mais do que preocupação humanitária com fatias populacionais em situação de pobreza, as práticas que se dispõem a controlar e/ou precaver ameaças objetivas constituem uma estratégia de governo.

Para Ewald (1991) nada é em si mesmo um risco, mas os eventos podem suscitar a possibilidade de riscos. As estratégias relativas à segurança fazem parte de uma racionalidade que procura rearranjar os elementos da realidade de modo a cercar os perigos possíveis. Ousaríamos dizer que os riscos estão relacionados à possibilidade de cerceamento de uma "vida normal", a partir de parâmetros construídos contingencialmente. Estar "em risco" ou constituir-se "como um risco" dependerá do lugar ocupado e das condições a que está submetido certo extrato da população. A infância é, atualmente, o segmento da população mais apontado como potencialmente em risco e que possibilita a fabricação de novos riscos.

Diferentemente da noção de perigo (a qual está relacionada à imprevisibilidade), o risco tem um componente probabilístico e caracteriza-se por uma forma de se relacionar com o futuro. A noção de risco visa à modificação do próprio presente, mediante a antecipação do futuro, que passa a reger a relação com o tempo atual (HILLESHEIM; CRUZ, 2008). Mediante o cálculo das 
probabilidades e do controle de todas as variáveis da vida, pode-se prever (e prevenir) o que irá acontecer. "Nesta perspectiva, o futuro é um tempo projetado no presente" (HILLESHEIM; CRUZ, 2008, p.197).

Robert Castel (2004) analisa que, paradoxalmente, as sociedades modernas, as quais são equipadas com um número infindável de bens materiais e de proteções, são aquelas onde o sentimento de insegurança atravessa todos os estratos sociais, levando-o a formular a hipótese que a insegurança moderna não se caracterizaria pela ausência de proteção, mas sim por uma busca frenética e incessante de segurança, a qual, por sua vez, retroalimentaria o sentimento constante de insegurança. Estar protegido seria então, estar armazenado. À medida que a sociedade alcança novas metas no que diz respeito à gestão da segurança, outras novas metas surgem, dando lugar a novos riscos até então inexistentes. Instaura-se, pois um constante mal-estar com relação ao porvir:

La imprevisibilidad de la mayor parte de esos "nuevos riesgos", la gravedad y el carácter irreversible de sus consecuencias, hacen que la mejor prevención consista a menudo en antecipar lo peor y en tomar medidas para evitar que eso advenga, aun cuando sea muy aletorio. (CASTEL, 2004, p. 78)

A noção de risco alimentaria assim uma demanda desesperada por segurança, dissolvendo a possibilidade de estar protegido. Na trama social a associação de proteções, vinculadas aos direitos sociais, converte o indivíduo em foco das atenções de instituições diversas, criadas para garantir tal asseguramento. Todo esse debate é fundamental para compreensão das formas de governo contemporâneas, sendo a gestão da segurança e do risco consideradas como operadoras das políticas públicas.

Segundo Cesar Candiotto (2011), a atuação recorrente dos dispositivos de segurança nos estados contemporâneos, mediante aparelhos encarregados da segurança pública e políticas de seguridade social, constitui uma sedimentação do biopoder na forma de biopolítica. O Estado de Bem-Estar social, em sua racionalidade, promove, por meio de uma reconfiguração da biopolítica4, "um novo

\footnotetext{
${ }^{4}$ Foucault (1997, p.89) descreve sumariamente biopolítica como "a maneira pela qual se tentou, desde o século XVIII, racionalizar os problemas propostos à prática governamental, pelos fenômenos próprios a um conjunto de seres vivos constituídos em população: saúde, higiene,
} 
pacto de segurança entre as instituições políticas e os cidadãos. A partir desse pacto, as instituições reguladas pelo Estado tentam garantir que a vida está protegida diante das mais diversas incertezas, acidentes, prejuízos e riscos" (CANDIOTTO, 2011, p. 91). Como exemplo situa-se a seguridade social nas áreas da saúde, economia e assistência social.

Quando esse pacto é rompido por qualquer um dos lados (cidadãos ou Estado) são acionados os dispositivos de segurança. No caso do rompimento pelos cidadãos, o Estado extrapola os limites jurídicos e intervém a partir de mecanismos extralegais, eliminando os potencialmente perigosos, justificando sua atuação em nome da vida da população. No caso do Estado romper o pacto, assevera Candiotto (2011), apesar da desconfiança da população em relação à garantia da vida por parte do Estado, tem-se a sensação de que a vida continua a ser regulada pelas instituições políticas. Isso se configura como uma regulação própria da biopolítica, pois, apesar de sob o ponto de vista jurídico uma das funções do Estado é a manutenção ou a restituição da ordem, "da perspectiva da racionalidade governamental, esses Estados atuam não para preservar o pacto e proteger as garantias individuais, mas para fortalecer a administração da desordem" (CANDIOTO, 2011, p.93), reforçando a necessidade de reconfiguração de sua soberania e de seu poder de matar e deixar morrer.

Nessa produção governamentalizadora, conduzir uma população não requer unicamente a extração e a formação de saberes sobre a mesma; há necessidade também de se produzirem registros para quantificar os seus aspectos mais característicos e propor intervenções, com base nos dados coletados. A utilização da estatística como conhecimento das forças e dos recursos que caracterizam o

natalidades, raças...". Esse poder sobre a vida desenvolveu-se em dois polos interligados: o primeiro polo centrou-se no corpo como máquina, no seu adestramento, na ampliação de suas aptidões, na extorsão de suas forças e no crescimento de sua utilidade e docilidade - a disciplina. O outro, centrou-se no corpo-espécie e seus processos biológicos: proliferação, nascimento, mortalidade processos feitos por meio de uma série de intervenções e controles reguladores da população. Tratase de "um novo corpo: corpo múltiplo, corpo com inúmeras cabeças, se não infinito pelo menos necessariamente numerável. A biopolítica lida com a população como problema político, como problema a um só tempo científico e político, como problema biológico e problema de poder, acho que aparece nesse momento" (FOUCAULT, 2005, p.292-293). 
governo possibilita a economia de poder e a utilização de estratégias de ação que guiarão as políticas de intervenção.

\begin{abstract}
As estatísticas formam uma lógica prática de causação, por meio da qual as características salientes do desenvolvimento e da natureza progressiva dos sistemas educacionais são constituídas. Ao mesmo tempo, as categorias e ordens de grandeza não são meros números que relatam a condição particular de uma nação. Os números contêm o acaso por meio das tecnologias das estatísticas. Isto é, fenômenos disparatados são ordenados e tornados comensurados para a administração social. Descortina-se uma uniformidade a respeito dos objetos que são contados e ordenados [...]. O que está em fluxo se torna estabilizado de modo a parecer apenas como um problema técnico restrito a um campo de objetividade (POPKEWITZ; LINDBLAD, 2001, p. 120).
\end{abstract}

Tendo como superfície de aplicação o corpo-espécie, a biopolítica intervém e controla práticas cujos focos são as taxas de natalidade, mortalidade, a saúde pública e a segurança, de modo a atingir a população tanto em termos biológicos quanto de poder. "Olhar e decifrar. Analisar e prescrever. Controlar e prever. Diagnosticar e predizer. Verbos que supõem atos, configurando, igualmente, uma gramática de práticas correlatas a uma ciência ou e a uma organização" (GONDRA, 2003, p. 27). O interesse pela vida e as formas de proporcionar sua segurança tornam-se elementos centrais para a gestão econômica. “A segurança constitui um tipo de racionalidade - formalizada pelo cálculo de probabilidades que coloca a intimidade das pessoas numa zona de governamento" (BUJES, 2011, p. 169).

Como uma tecnologia de governo, o saber estatístico tem criado regularidades as quais têm sido postas nas populações, tornando-se necessárias e pertinentes à sua gestão, objetivando administrar e otimizar as condutas individuais e coletivas, desde o nascimento. Quanto mais informações são produzidas, mais cálculos e probabilidades são apresentados, maiores são o escrutínio e a complexificação da vida. A informação produz a (a)normalização, regra as condutas, produz os bem sucedidos e os desviantes.

De acordo com Popkewitz e Lindblad (2001) a construção de classes de pessoas, a sua classificação produz, por si própria, biografias para o indivíduo, o qual é definido "de maneira normativa em relação a agregados estatísticos a partir dos quais as características específicas podem ser atribuídas a essa pessoa e 
segundo as quais seu crescimento e desenvolvimento podem ser monitorados e supervisionados" (2001, p. 131). A diferença converte-se em risco:

Estar fora (do prescrito) e ao mesmo tempo dentro (presença que se impõe
em nosso convívio cotidiano), distante (do que se deseja) e tão
incomodamente próximo (de nós - os adequados) constitui o que chamo
de risco-diferença. [...] Assume, portanto, novos sentidos que se
produzem pelo cruzamento de uma série de discursos contemporâneos
que falam a "verdade" acerca da infância, da adolescência, da organização
familiar, da educação, do trabalho (HÜNNING, 2007, p. 150, grifos da
autora)

O risco-diferença figura nos mais diferentes espaços: na pobreza, no ócio, no meio em que se vive e frequenta, nos fazeres e nos não-fazeres, nos saberes e nãosaberes, nos modos de querer e pensar, nas famílias e na infância, conjugada a um ou mais fatores anteriores. Com os diversos investimentos sobre a população está cada vez mais difícil apontar os excluídos, uma vez que, de certa forma, o Estado abarca, por meio das inúmeras políticas apontadas, a população como um todo, operando numa lógica de cidadanização. Conforme Maura Corcini Lopes (2011, p.286) a diminuição dos "excluídos" faz, no entanto, aparecer outras categorias, os desfiliados, os reclusos, os em situação de vulnerabilidade social.

A norma, ao operar como um princípio de comparabilidade, age no sentido de incluir a todos, por meio da homogeneização das pessoas, quanto pela “banalização das diferenças identitárias que caracterizam os indivíduos dentro das suas comunidades" (LOPES, 2011 p. 288). Nas operações de normalização investese na inclusão dos desviantes à área da normalidade (cada vez mais plural e alargada), minimizando certos traços e dificuldades, por meio de criação de políticas de assistência e de inclusão social e educacional. É comum depararmo-nos com políticas que enaltecem a diversidade, mas ao mesmo tempo a essencialidade da infância, numa forma de tornar rotineira as diferenças a que as crianças estão submetidas.

Tal racionalidade de governo se posta de forma a dirigir as intervenções no que diz respeito ao governo da população infantil. Na gestão da vida das crianças os riscos podem estar localizados em pontos diferentes, às vezes até considerados como incongruentes, tais como na saúde, na estrutura e renda familiar, no grau de escolarização dos pais, na frequência à escola, dentre outros. Técnicas de segurança 
são, então, recursos para a contenção dos riscos fabricados. Tais dispositivos acabam por compor o sujeito infantil moral, num agenciamento das suas vontades e governamento das suas condutas.

A inclusão da população em programas de assistência e educação visa assegurar as condições básicas de sobrevivência dos indivíduos, ao mesmo tempo, incluí-las no jogo do mercado "gerenciando e minimizando os riscos que aqueles cobertos por tais políticas representam para si mesmos, para os outros e para o Estado" (LOPES, 2011, p. 293). Antecipação, no presente, dos prejuízos futuros causados pelas populações definidas como potencialmente perigosas. Crianças em perigo/perigosas: figuras de controle. A narrativa do cuidado transformada agora pela do risco, institui de forma diferenciada o discurso do controle. Os meandros do existir devem ser canalizados de forma a produzir cada vez mais caminhos já desenhados e escrutinados. Felicidade é norma.

\section{Crianças felizes: cuidado, resiliência e (auto)conhecimento}

Aprende a ler, a escrever, a contar, a falar

Em seu leito de morte Nazira ordena à Nawal que lute contra a miséria a que seu povo está inserido por meio do que acredita ser o caminho para uma vida outra: aprender a ler, a escrever, a contar, a pensar. Esse foi o caminho trilhado por Nawal a partir de então e o nome de sua avó em seu túmulo foi a primeira inscrição de saída desse mundo cercado pela violência e pela pobreza. Guerrear pela/na palavra seria a chave para a felicidade.

Hoje, o imperativo para a felicidade não é apenas esse. É fundamental aprender a expressar-se, a narrar-se e, com certeza, corrigir-se. Uma espécie de saturação intimizante da vida do infantil posta-se como necessária. Ao adulto caberia a responsabilidade de cada vez mais conhecê-lo, cercá-lo, protegê-lo até de si mesmo, de suas possíveis frustrações, tristezas, humores. Nem muito alegre (pode ser hiperativo), nem muito triste ou quieto (pode ser depressivo). É 
necessário ainda conhecer suas preferências, suas opiniões e alegrias, enfim, fazê-lo reinar em sua infante soberania. Entendamos, porém, que esse reinado é somente uma ponta de uma racionalidade vigente, onde todos (nós) somos governados, sem exceção.

Trata-se, entendemos, da celebração de uma política de governo da subjetividade, a qual engloba os âmbitos público e privado da vida e incorpora as questões subjetivas às técnicas governamentais, de modo a envolvê-las na relação que cada indivíduo tem consigo mesmo. As linhas de força que atuam nessa política colaboram para reforçar a ideia do cidadão "em busca de", ser que mira à felicidade e que, para alcançá-la, efetua sobre si operações de administração sobre seu corpo e sua alma.

A busca da felicidade é apontada, além de um direito a ser perseguido individualmente, um dever dos governos, felicidade esta definida, por exemplo, como bem-estar psicológico, satisfação pessoal, saúde, gestão do tempo, padrão de vida, educação, cultura, governança etc.

O que antes era um direito negativo - os aparelhos de Estado não deveriam obstar o exercício do direito de cada um perseguir a própria felicidade -, tornou-se, a partir da implantação do modelo de Estado de bem-estar social (Welfare State), uma incumbência das políticas governamentais. Propiciar e chancelar o bem-estar psicológico, a sensação de satisfação e conforto em relação à própria vida, instituídos como tarefa da política, não deixa de ser uma das mais atuais estratégias de subjetivação-dessubjetivação. (CORRÊA, 2009, n. p.)

A partir da premissa de que a felicidade é um direito a ser conquistado e de que a criança, na condição de cidadão, tem que ser acolhida em suas necessidades básicas, seus desejos e sentimentos, faz-se essa conquista (de uma vida feliz) uma obrigação do Estado, da sociedade e da família. Seja no nível pessoal, seja na coletividade e nos governos, o tema da felicidade é recorrente, ensejando um tipo de ascese no indivíduo que se subjetiva como cidadão potencialmente feliz, bem como promovendo intervenções nas ações estatais que possibilitem a "procura" da felicidade. A despeito de existirem atualmente inúmeros índices sociais para medir a felicidade de uma nação, a cada dia surgem novos estudos que procuram pormenorizar as condições/requisitos que entram na "conta da felicidade", além de dar uma característica mais peculiar, dependendo da especificidade de cada país. 
Tal modo de ordenamento do mundo tem um passado em certa parte recente. Com o advento da Modernidade, a estatização de diferenciados setores da vida foi alimentada sob uma ideia de felicidade diferenciada das demais até então. Se nos voltarmos ao século XVIII, encontraremos em Jeremy Bentham, filósofo e jurista da época, uma noção que nos é cara até hoje. Para o pensador:

a maneira como qualquer pessoa devia buscar a felicidade era um assunto
a ser resolvido pelo indivíduo em questão. Mesmo assim, em primeiro
lugar, alguém tinha de assegurar que essa busca seria possível - e isso era
o trabalho do governo: criar condições que permitissem que todos nós
buscássemos a felicidade da maneira que achássemos melhor. (SCHOCH,
2011, p. 38)

Para o que seria uma efetiva ação do governo, Jeremy Bentham (1979) criou o cálculo felicífico, ou a equação da felicidade, a qual pode ser resumida na equação felicidade é igual a prazer menos dor. Tal acepção denota uma busca racional da felicidade e uma ação econômica do Estado, no sentido de garantir a liberdade (salvaguardando a vida e a propriedade) do indivíduo para a sua satisfação pessoal. A liberdade, nomeada por Bentham como segurança, não garantiria sozinha a felicidade, pois caberia, em última instância, ao indivíduo o "querer" ser feliz. O Estado só agiria em casos de (im)probidade, ou seja, quando a busca da felicidade individual obstruísse a felicidade de outra pessoa, sendo então justificadas ações coercitivas e proibitivas.

Michel Foucault destaca, em seu texto Omnes et Singulatim: uma crítica da razão política, que a arte de governar de Estado, a qual floresceu a partir séculos XVI e XVII, no objetivo de aumentar sua potência, utilizou-se de técnicas de governo próprias, que apelavam para a sua intervenção. A polícia, uma de tais técnicas, deveria velar pela preservação da vida. "Em suma, a vida é objeto da polícia: o indispensável, o útil e o supérfluo. Cabe à polícia permitir aos homens sobreviver, viver e fazer melhor ainda" (FOUCAULT, 2006, p. 381). Este melhor estaria relacionado "à maior felicidade de qual ele (o homem) possa gozar dessa vida" (op. cit.).

Nesse sentido, poderíamos dizer que, atualmente, convivemos com um "estado de polícia" permanente. Instigados a procurarmos a felicidade em todos os locais que habitamos, somos relembrados cotidianamente e, até mesmo, 
ininterruptamente, acerca do que seria a nossa mais cara missão: construirmos um mundo feliz (para cada um e para todos), tornando-nos a nossa própria polícia. $\mathrm{O}$ Estado age por meio de políticas de intervenção diversas (na segurança, na moralidade, na saúde, na educação, na economia, na assistência social etc.), algumas dessas pautadas principalmente em ações de orientação e formação, porém a responsabilização pela conquista (ou não) da felicidade, apesar de tutelada pelo governo, é de caráter subjetivo.

Um dos ingredientes da pílula da felicidade para as crianças é, segundo tais referenciais, o autoconhecimento, o qual passa pela aprendizagem da percepção que as crianças têm acerca de si mesmas, suas intenções, pensamentos e sentimentos que as torna aprendizes confiantes, os quais desenvolvem sua autoestima e um sentido de si (SÃO PAULO, SECRETARIA MUNICIPAL DE EDUCAÇÃO, 2007). O escrutínio dessa racionalidade nos remete à temática do cuidar, entendido não só como ato ligado à promoção da saúde e de hábitos higiênicos, mas como uma teia de ações que promovem, conforme propalado, o bem-estar físico, mental e psicológico.

Documentos institucionais reverberam essa lógica de forma muito explícita:

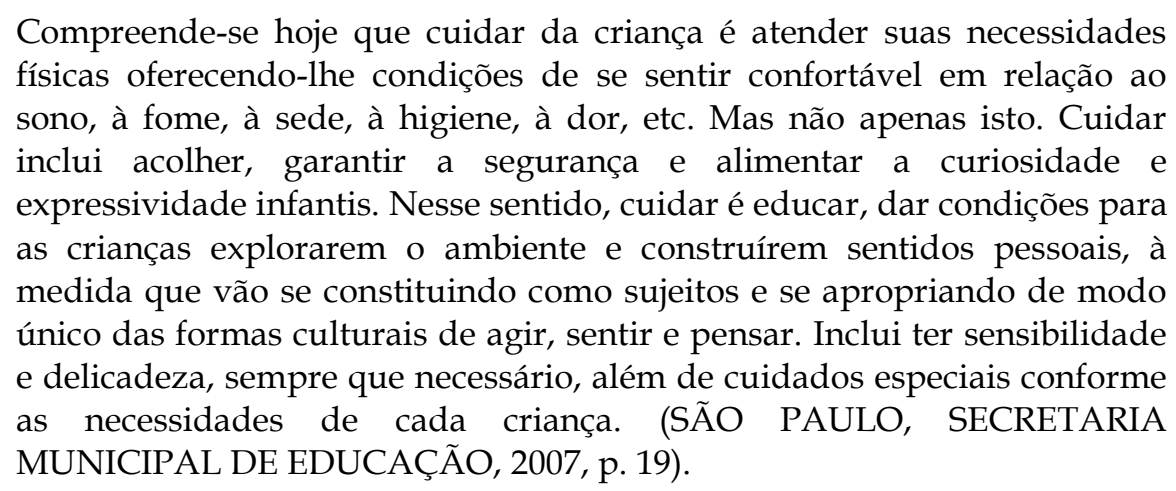

Máquinas de "fazer falar", de autoexpressão, os documentos que delineiam as políticas públicas para educação, saúde e assistência social coadunam os objetivos delineados para a infância e sua educação com sugestões e relatos de práticas exitosas com as crianças. Estas, "falando livremente, entre uma brincadeira e outra, entre um desenho e uma colagem, [...] contam suas histórias e dizem quem são" (REDE NACIONAL PRIMEIRA INFÂNCIA, 2011, p.7): “Família é estar junto"; "Falta paz e alegria em casa, todo dia sai briga"; "Quando eu brinco fico 
feliz"; "Eu sei que pode escrever o que a gente pensa. Pode, não é?"; "Ter uma carteira, ter dinheiro, isso eu quero quando crescer"; “Quem tem um amigo é muito feliz" (op. cit.).

A inserção, nos discursos proliferados em prol de um investimento cada vez mais antecipado na infância, da importância da educação da infância para o desenvolvimento de, (UNICEF, 2008), opera numa lógica governamentalizadora de cunho neoliberal. São termos de inspiração psi que se coadunam com os interesses mercadológicos de produtividade e elevação do poder de compra.

Operando um deslocamento da lógica liberal, o neoliberalismo produz mecanismos de incitação à liberdade, sob a forma de competição (VEIGA-NETO, 2011). Passa-se então de uma sociedade de produtores para uma sociedade de consumidores, onde a liberdade é produzida e consumida ao mesmo tempo. Mais do que "fazer uso de", consumir representa pertencer a um novo mundo, um mundo criativo, o qual exige dos indivíduos que nele habitam a capacidade de gerir sua própria vida com seus (in)fortúnios. Destaque há de ser dado ao conceito de resiliência, o qual ultimamente tem sido validado por todos os campos do saber, em especial a educação e a psicologia, respingando na configuração das políticas dirigidas às crianças e jovens.

A resiliência, capacidade de o indivíduo sobreviver às adversidades de toda ordem, convoca a todos ao esforço pelo crescimento pessoal, em uma lógica fomentadora do mérito. Felicidade e sucesso são metas a serem perseguidas. Opera-se desde a tenra idade, numa lógica de produção de sujeitos autogovernáveis, que se auto regulam e que são incitados diuturnamente a fazer escolhas por meio da liberdade que lhes foi conferida e conquistada. Crianças e jovens resilientes, "aqueles que tudo suportam, toleram e acolhem" (OLIVEIRA, 2011, p. 92), são cidadãos apaziguados:

uma educação para a resiliência [...], valorizada na formação, produção e restauração da melhoria de si e da melhoria dos outros, pelo assemelhamento resiliente do mesmo para chegar, por outras vias, ao vínculo entre tolerância e segurança. Semelhança dissolvida e ao mesmo tempo renovada nas medições e projeções de cálculos probabilísticos governáveis, voltados ao governo de todos por cada um (portanto, democrático); medianos e individualizados (derivados de incontáveis nivelamentos pastorais); de suportar um impacto e refazer o estado 
original, não como aquele que era, mas modulado por estados conformados ao que pretende ser em condições de tolerância e, desta maneira, pela capacidade de sustentar um determinado estado governável e governado, pela vida tomada sob controle e gestão resiliente (OLIVEIRA, 2011, p.97-98).

A individualização da responsabilização torna-se uma tônica a ser proclamada. O investimento cada vez mais precoce na criança e nas suas competências pessoais, dentre as quais se destaca a autonomia e a criatividade, coaduna-se com um apagamento de pontos de resistência, uma vez que é imputada ao indivíduo uma ideia de conquista pelo mérito (SCHILLING, 2013, 2014).

Com fulcro nesse debate analítico, Jorge Larrosa (1994) traz à baila a questão da dobradura reflexiva, a qual faz com que o sujeito, a modo de uma certa ascese, constitua-se por meio do discurso da expressividade:

[...] não se trata do fato de que a pessoa aprende meios de expressão de si mesma. O que ocorre, antes, é que, ao aprender o discurso legítimo e suas regras em cada um dos casos, ao aprender a gramática para a autoexpressão, constitui-se ao mesmo tempo o sujeito que fala e sua experiência de si. Não se trata de que a experiência de si seja expressada pelo meio da linguagem, mas, antes, de que o discurso mesmo é um operador que constitui ou modifica tanto o sujeito quanto o objeto da enunciação, neste caso, o que conta como experiência de si (LARROSA, 1994, p. 67-68).

A construção da felicidade do homem, desde a sua tenra idade, depende, assim, de uma série de intervenções sobre si mesmo, reguladas por uma disposição de técnicas, táticas e formas de governo: o Estado regulando as condições de vida do cidadão, por meio de dispositivos de saber-poder, que esquadrinham suas condições de existência mapeiam suas faltas e necessidades, incitam seus desejos, promovem e controlam a manutenção da bios. O delicado jogo de fazer viver/deixar morrer prevê cálculos atualizados diuturnamente, estratégias diferenciadas visando situações diversas e um controle das disposições, em cada âmbito da sociedade. A criança não escaparia desse refinamento de ações.

\section{A infância e suas figuras: algumas questões finais}

Buscamos, a partir desta breve exposição, dar a ver uma linha de análise que se arregimentou em duas recorrências discursivas acerca das figuras da infância na atualidade: a do risco e a da busca da felicidade. A narrativa de "Incêndios" nos 
remete a dialogarmos intensamente com tais figuras. A história de Mouawad é tecida pelo discurso da violência, da pobreza, da violação de direitos e, principalmente, da memória como constituidora de um sujeito que se perfaz à medida que se conhece e se descobre. A busca por um "eu" que se encontra e se desvenda é cerzida pelo embate com a origem. Esta, acreditamos, é o fim condutor de uma história em que a felicidade foi buscada no encontro. "Para além do silêncio. Tem a felicidade de estar junto. Não há nada mais lindo que estar juntos" (MOUAWAD, 2013, p. 129).

As reiterações argumentativas dos discursos do risco e da felicidade estão alicerçadas num projeto de manutenção da vida. Fazer viver, cada vez melhor, com mais condições e por mais tempo, compensar as deficiências e propor práticas mais (auto)reguladoras.

O discurso do risco é tensionado pelas linhas concorrentes da vulnerabilidade da infância e da periculosidade que a mesma pode representar. Em ambas vertentes, o que se propõe é a intervenção precoce na criança e em sua família, por meio de ações na área da saúde, educação e assistência social. O duplo risco-segurança torna-se modelo produtivo, o qual promove discursos nos meios de comunicação de massa, cria políticas de saúde e educação e produz saberes "que promovem e promovem-se na gerência sobre si e na responsabilidade pessoal e culpabilização dos indivíduos pelos próprios sucessos e insucessos existenciais" (CARVALHO, 2007, p.148). A oferta e a disponibilização de informações e conhecimento sobre os indivíduos alimenta uma pedagogia do autodidatismo (op. cit.), que conduz os sujeitos à busca de sua autorrealização. A sistemática de antecipação do futuro prevê o surgimento de eventos indesejáveis, tais como doenças, comportamentos desviantes e anormais, numa tônica de responsabilização do indivíduo pelo seu (in)sucesso - a gerência da vida passando pelo próprio indivíduo.

A busca da felicidade, trabalho a ser perseguido e efetivado por cada um, como um dos deveres dos estados ocidentais listados desde a carta da independência norte americana, remalha o discurso do risco e da criança como cidadã. Tudo o que se projeta, faz-se em nome de uma felicidade, a qual se traveste 
em bem-estar, saúde, independência econômica e, principalmente, normalidade. Os índices criados forjam a participação da sociedade e asseguram o direito à opinião e ao livre arbítrio.

Uma nova relação se estabelece entre o poder e a vida configurando uma invasão performática de âmbitos os quais achávamos impenetráveis, "os gens, o corpo, a afetividade, o psiquismo, até a inteligência, a imaginação, a criatividade, tudo isso foi violado, invadido, colonizado [...]" (PELBART, 2009, n.p.). Utilizandose de mecanismos esparramados, polimorfos e rizomáticos ${ }^{5}$, o biopoder contemporâneo age nas formas de sentir, pensar, amar e comportar-se. Intensificar e otimizar a vida, a partir da cooptação dos desejos e necessidades.

Dir-nos-ia Agamben (2008), que de viventes passamos a sobreviventes, à vida reduzida ao mínimo biológico. “Estamos todos reduzidos ao sobrevivencialismo biológico, à mercê da gestão biopolítica, cultuando formas de vida de baixa intensidade, subestimada à morna hipnose consumista, mesmo quando a anestesia sensorial é travestida de hiperexcitação" (PELBART, 2009, n.p.). Assim, nos voluntariamos a bioasceses onde o self almejado, na maioria das vezes, expressa uma "vontade de uniformidade, de adaptação à norma e de constituição de modos de existência conformistas e egoístas" (ORTEGA, 2003, p. 63).

A conquista da felicidade, ao lado da liberdade, constitui-se como um parâmetro para as democracias-mercado. Tal como assevera PELBART (2000), o consenso democrático transforma o moderno cidadão em homem médio, que pasta entre serviços e mercadorias ofertadas. Consumir cada vez mais: mercadorias, ideias sobre o mundo e sobre si mesmo. Esse apelo à busca incessante por uma completude consubstancia-se numa política que valoriza cada vez mais o

\footnotetext{
${ }^{5} \mathrm{Na}$ biologia, um rizoma é uma estrutura componente em algumas plantas cujos brotos podem ramificar-se em qualquer ponto e transformar-se em um bulbo ou um tubérculo. Este rizoma pode funcionar como raiz, talo ou ramo, independente de sua localização na planta. O rizoma tem a capacidade de conectar um ponto a qualquer outro. Para Deleuze e Guattari (2009), esse conceito pode ser ampliado filosoficamente indicando que não há um ponto de origem ou princípio primordial que organiza todo o pensamento. O rizoma é "um sistema a-centrado não hierárquico e não significante (...) unicamente definido por uma circulação de estados" (DELEUZE; GUATTARI, 2009, p. 33). Tal conceito, articulado ao de biopoder, confere a este último uma característica de rede de relações que se espalham pelo corpo-espécie. O biopoder foi um dos elementos indispensáveis para o desenvolvimento do capitalismo, assegurando a inserção dos corpos no aparato produtivo e da população nos processos econômicos. (CASTRO, 2009, p. 58).
} 
autoconhecimento e a conquista da autonomia do indivíduo, como formas de expressão da cidadania.

Desse modo, as intervenções contínuas das ciências, especialmente a psicologia e a pedagogia, no sentido de intensificarem as experiências em que o sujeito é "levado" a encontrar-se consigo mesmo, com o objetivo de conhecer-se e construir sua autonomia, conduziriam, paradoxalmente à obediência ao outro, representado aqui por uma lógica governamental racionalizadora das condutas humanas. "Quanto mais eu me procuro, tanto mais obedeço ao outro" (GROS, 2008, p. 137). Parece-nos que o infantil, ao tomar o lugar de "falante", cidadão de direitos, e por consequência um constante "vasculhador" de sua própria felicidade, deslocou-se de uma zona da anormalidade para figurar no espaço da norma. E em tal deslizamento, sob o diapasão da liberdade, é investido a aprender a governar-se, para ser melhor governado.

Em que pese ser a tutela das novas gerações uma necessária incumbência dos mais velhos, a crítica aos discursos sobre a infância, à inspiração da leitura de "Incêndios" e da trajetória de Nawal, permite-nos recompor as lógicas que constituem uma forma de circunscrever a existência, resultado que é do incessante embate entre governo e liberdade: sua emergência e proveniência. Tal atitude analítica impõe o desalojar do tranquilo, confortável e morno terreno da verdade as práticas que a constituem.

Significa, pois, postar a própria verdade no sítio da produção, da contingência e não da essência originária: não há descoberta da verdade da infância, mas a produção de uma verdade; não há o modo de vida feliz, mas o investimento em práticas que, pelo seu rebatimento e reiteração, produzem dados efeitos e constrangimentos na forma da vida. Quais? O que está em questão nesses discursos, nesses ordenamentos, não é o infantil, a criança, mas um modo de pensar, narrar-se e narrar o outro, sentir, agir e investir a existência, o que nos alcança a todos para, quiçá, "salvar a dignidade do aterrorizante pequeno tédio" (MOUAWAD, 2013, p. 125). Ora, o que se produziu pode ser posto em causa; os cenários podem ser tomados como inflamáveis - incendiários e incendiáveis. A existência pede calor. Um exercício obstinado do pensamento, como o da 
protagonista de Incêndios, acerca daquilo que nos produziu lega-nos a possibilidade da recusa e da invenção. Afinal... (Jeanne, em sala de aula) "Vocês não vão conseguir. Toda teoria dos grafos repousa essencialmente sobre esse problema por enquanto impossível de ser resolvido. Ora, é essa impossibilidade que é linda" (MOUAWAD, 2013, p. 37).

\section{Referências}

BENTHAM, Jeremy; STUART MILL, John. Uma Introdução aos Princípios da Moral e da Legislação (Coleção Os Pensadores). São Paulo: Abril Cultural, 1979.

BRASIL. Constituição (1988). Constituição da República Federativa do Brasil. Organização de Alexandre de Moraes. 16. ed. São Paulo: Atlas, 2000.

BUJES, Maria Isabel Edelweiss. Infância e Risco. Educação \& Realidade. Porto Alegre, v. 35, n. 3, p. 157-174, set./dez. 2011.

CARVALHO, Mónica. Risco, dispositivos de informação e a questão do governo em sua relação com a saúde nas sociedades contemporâneas. Estudos em Comunicação n. 2, p. 147-170, dez. 2007.

CANDIOTTO, Cesar. Cuidado da vida e dispositivos de segurança: a atualidade da biopolítica. In: CASTELO BRANCO, Guilherme; VEIGA-NETO, Alfredo. Foucault: filosofia e política. Belo Horizonte: Autêntica, 2011. p. 81-96.

CASTEL, Robert. La inseguridad social. Qué es estar protegido? Buenos Aires: Manantial, 2004.

CASTRO, Edgardo. Vocabulário de Foucault: um percurso pelos seus temas, conceitos e autores. Revisão Técnica Alfredo Veiga-Neto e Walter Omar Kohan. Belo Horizonte: Autêntica Editora, 2009.

CORREAA, Murilo Duarte Costa. Máquinas de fazer sorrir: notas sobre uma economia da felicidade. Disponível em:

<http:/ / murilocorrea.blogspot.com/2009/11/maquinas-de-fazer-sorrir-notassobre_25.html>. Acesso em: 15 dez. 2011.

DELEUZE, Giles; GUATTARI, Félix. Mil Platôs: Capitalismo e Esquizofrenia. Coordenação da Tradução Ana Lúcia de Oliveira. São Paulo: Editora 34, 2009.

EWALD, François. Insurance and risk. In: BURCHELL, Graham; GORDON, Colin; MILLER, Peter. The Foucault effect: studies in governmentality. Chicago: The University of Chicago Press, 1991. p. 281-298. 
FERREIRA, Patrícia Helena. Tramas e Grades: inventários sobre a criança na educação infantil. Tese de Doutoramento, Faculdade de Educação da Universidade de São Paulo, 2013.

FOUCAULT, Michel. Resumo dos cursos do Collège de France (1970-1982). Tradução Andréa Daher. Consultoria Roberto Machado. Rio de Janeiro: Jorge Zahar Editores, 1997.

Em defesa da Sociedade. Tradução Maria Ermantina Galvão. São Paulo: Martins Fontes, 2005.

Omnes et Singulatim: uma crítica da razão política. In: FOUCAULT, M. Estratégia, Poder-Saber. Ditos E Escritos IV. Tradução Vera Lúcia Avellar Ribeiro; [organização e seleção de textos Manoel Barros da Motta]. Rio de Janeiro: Forense Universitária, 2006. p. 355-385.

Nietzsche, a Genealogia e a História. In: FOUCAULT, M. Arqueologia das ciências e História dos Sistemas de Pensamento: Ditos E Escritos II. 2. ed. Tradução Elisa Monteiro; [organização e seleção de textos Manoel Barros da Motta]. Rio de Janeiro: Forense Universitária, 2008. p. 260-281.

GONDRA, José Gonçalves. Homo Hygienicus: educação, higiene e a reinvenção do homem. Caderno Cedes, Campinas, v. 23, n. 59, p. 25-38, abr. 2003.

GROS, Frédéric. O cuidado de si em Michel Foucault. In: RAGO, Margareth; VEIGA-NETO, Alfredo (orgs.). Figuras de Foucault. 2. ed. Belo Horizonte: Autêntica, 2008. p. 127-138.

HILLESHEIM, Betina; CRUZ, Lílian Rodrigues da. Risco, vulnerabilidade e infância: algumas aproximações. Psicologia E Sociedade, 20 (2), p.192-199, 2008.

HÜNNING, Simone Maria. Psicologia: da (a)normalidade ao risco. In: GUARESCHI, Neuza Maria De Fátima; HÜNNING, Simone Maria (orgs.). Implicações da psicologia no contemporâneo. Porto Alegre: EDIPUCRS, 2007. p. 135-157.

LARROSA, Jorge. Tecnologias do eu e educação. In: SILVA, Tomaz Tadeu da (Org.). O Sujeito da Educação: estudos foucaultianos. Petrópolis: Vozes, 1994. p. 3586.

LAZZARATTO, Marcelo; GONÇALVES, Michelle. Ifigênia e o Campo de Visão: poesia visionária. Pitágoras 500, Campinas, v. 4, p. 39-53, abr. 2013.

LAZZARATO, Marcelo. Ifigênia e o campo de visão: o entrelaçar entre o tema e a linguagem. Revista Sobe - Cia Elevador de Teatro. Ano II, n. 2, São Paulo, p. 4-8, 2012. 
LOPES, Maura Corcini. Norma, inclusão e governamentalidade neoliberal. In: CASTELO BRANCO, Guilherme; VEIGA-NETO, Alfredo. Foucault: filosofia e política. Belo Horizonte: Autêntica, 2011. p. 283-298.

MARÍN-DÍAZ, Dora Lilia. Morte da infância moderna ou construção da quimera infantil? Educação \& Realidade, Porto Alegre, v. 35, n. 3, p. 193-211, set./dez. 2010.

MOUAWAD, Wadji. Incêndios. Rio de Janeiro: Cobogó, 2013.

Littoral: volume 1, Le sang des promesses. Arles, France: Actes Sud, 1999.

OLIVEIRA, Salete. Política e fissuras sobre crianças e jovens: psiquiatria, neurociência e educação. Ecopolítica. n. 1, p. 77-103, 2011. Disponível em: $<$ http://revistas.pucsp.br/index.php/ ecopolitica/article/view/7657/5740>. Acesso em: 10 fev. 2012.

ORGANIZAÇÃO DAS NAÇÕES UNIDAS - ONU. Um mundo para as crianças. Relatório do Comitê Ad Hoc Pleno da vigésima sétima sessão especial da Assembleia Geral Nações Unidas. Nova Iorque, 2002.

ORTEGA, Francisco. Práticas de ascese corporal e constituição de bio-identidades. Cadernos Saúde Coletiva (UFRJ), Rio de Janeiro, v. XI, n. 1, p. 59-77, 2003.

PELBART, Peter Pál. A vertigem por um fio: políticas da subjetividade contemporâneas. São Paulo: Iluminuras/FAPESP, 2000.

Vida nua, vida besta, uma vida. Trópico. Disponível em:

<http://p.php.uol.com.br/tropico/html/textos/2792,1.shl>. Acesso em: 15 mar. 2009.

POPKEWITZ, Tom; LINDBLAD, Sverker. Estatísticas educacionais como um sistema de razão: relações entre governo da educação e inclusão e exclusões sociais. Educação \& Sociedade. Ano XXII, n. 75, p. 111-148, ago. 2001.

PIRES, Cássio. Ifigênia. Revista Sobe - Cia Elevador de Teatro. Ano II, n. 2, São Paulo, p. 47-70, 2012.

RAGO, Margareth; VEIGA-NETO, Alfredo (orgs.). Figuras de Foucault. Belo Horizonte: Autêntica, 2006.

RAMOS DO Ó, Jorge. O governo de si mesmo: modernidade pedagógica e encenações disciplinares do aluno liceal (último quartel do século XIX - meados do século XX). Lisboa: Educa, 2003.

REDE NACIONAL PRIMEIRA INFÂNCIA. Deixa eu Falar! Brasília: MEC, 2011. 
SÃO PAULO. Secretaria Municipal de Educação. Diretoria de Orientação Técnica. Orientações curriculares: expectativas de aprendizagens e orientações didáticas para Educação Infantil. São Paulo: SME / DOT, 2007.

SCHILLING, Flávia. Igualdade, desigualdade e diferenças: o que é uma escola justa? Educação e Pesquisa (USP. Impresso), v. 39, p. 31-48, 2013.

. Educação e Direitos Humanos. Percepções sobre a escola justa. São Paulo: Cortez, 2014.

SCHOCH, Richard. A história da (in)felicidade: três mil anos de busca por uma vida melhor. Rio de Janeiro: BestSeller, 2011.

UNICEF BRASIL. Situação da infância mundial 2008: caderno Brasil. Brasília, 2008. Disponível em: <http://www.unicef.org/brazil/pt/cadernobrasil2008.pdf>. Acesso em: 01 nov. 2011.

VEIGA-NETO, Alfredo. Governamentalidades, neoliberalismo e educação. In: CASTELO BRANCO, Guilherme; VEIGA-NETO, Alfredo. Foucault: filosofia e política. Belo Horizonte: Autêntica, 2011. p. 37-52.

VERNANT, Jean-Pierre. Mito e tragédia na Grécia antiga. $2^{a}$ ed. São Paulo: Perspectiva, 2011. 